\title{
Wpływ parametrów zgrzewania wybuchowego na własności bimetalu S355J2N - AW1050A
}

\author{
Influence of explosive welding parameters \\ on bimetal S355J2N - AW1050A properties
}

\section{Streszczenie}

W artykule przedstawiono wyniki badań bimetalu S355J2N - AW1050A wykonanego technologią zgrzewania wybuchowego. Ocenie poddano wpływ wysokości warstwy materiału wybuchowego $(\mathrm{H})$ na własności bimetalu. W celu weryfikacji tego parametru przeprowadzono analizę zmian mikrotwardości w strefie połączenia, określono charakterystykę geometrii złącza oraz wykonano technologiczne próby odrywania i gięcia. Na podstawie przeprowadzonych badań stwierdzono, że zmiana wysokości warstwy materiału wybuchowego nie wpływa na twardość w strefie połączenia, jednak ma ona znaczny wpływ na geometrię złącza oraz wytrzymałość bimetalu.

Słowa kluczowe: zgrzewanie wybuchowe; S355J2N, AW1050A, geometria złącza, mikrotwardość

\begin{abstract}
The article shows the results of research on clad material S355J2N - AW1050A. Were evaluated the impact of the heigth of explosive material layer on the properties of bimetal. In order to verify this parameter, were performed such tests as: analysis of changes in microhardness, analysis of the geometry of joint, ram strength tests and bend tests. Based on performed reasearchs, was found that the change of highness of the explosives does not effect on the hardness of the bimetal. However, it has a significant effect on the results obtained during the ram strength test and bending test, as well as on the geometry of the joint.
\end{abstract}

Keywords: explosive welding; S355J2N, AW1050A, geometry of joint, microhardness

\section{Wstęp}

Technologia zgrzewania wybuchowego metali daje unikalne możliwości łączenia materiałów o skrajnie odmiennych właściwościach, takich jak skład chemiczny, temperatura topnienia, plastyczność itp. Zwykłe różnice te nie pozwalają na zastosowanie tradycyjnych metod łączenia dyfuzyjnego, które w wielu przypadkach powodują występowanie w złączu kruchych związków intermetalicznych. Technologia spajania wybuchowego nie posiada takich ograniczeń, a właściwy dobór parametrów procesu pozwala uzyskać połączenie o bardzo dobrych własnościach wytrzymałościowych [1,2]. Przykładem połączenia, które otrzymano tą metodą jest bimetal stal węglowa S355J2N + aluminium AW1050A. Materiał ten może być wykorzystany jako anoda do aktywnej elektrochemicznej ochrony przeciwkorozyjnej. W tym przypadku istotnym jest dobór parametrów zgrzewania wybuchowego, w celu uzyskania złącza o jak najlepszej jakości. Do parametrów zgrzewania wybuchowego zalicza się między innymi wysokość warstwy materiału wybuchowego $(\mathrm{H})$ oraz wstępną odległość pomiędzy zgrzewanymi materiałami $[1,3]$.
W pracy porównywano parametry złącza oraz jego własności mechaniczne (próba odrywania oraz zginania) dla zastosowanych różnych wysokości warstwy materiału wybuchowego $(\mathrm{H})$. Dla wszystkich wykonanych prób, wstępny dystans pomiędzy łączonymi materiałami był jednakowy.

\section{Techniki badawcze}

\section{Materiał do badań}

W ramach prowadzonych badań wykonano technologią zgrzewania wybuchowego 3 płyty bimetalowe o wymiarach 1000 x 2000 mm, dla których przyjęto zmienną wysokość warstwy materiału wybuchowego $(\mathrm{H})$ przy stałej wstępnej odległości pomiędzy zgrzewanymi blachami. Parametry zgrzewania wybuchowego oraz oznaczenia próbek przedstawiono w tabeli I. W analizowanym układzie materiałem podstawowym była blacha ze stali węglowej S355J2N o grubości $5 \mathrm{~mm}$, natomiast materiałem nakładanym blacha z technicznie czystego aluminium AW1050A o grubości

Mgr inż. Michał Najwer, mgr inż. Grzegorz Kwiatkowski - Politechnika Opolska, mgr inż. Urszula Sobczak - Wojskowa Akademia Techniczna.

Autor korespondencyjny/Corresponding author. michal1656@gazeta.pl 
$5 \mathrm{~mm}$. Skład chemiczny łączonych materiałów przedstawiono w tablicach II i III. Po wykonaniu układów bimetalowych, dla wszystkich płyt wykonano badania ultradźwiękowe, które wykazały, że materiały zostały połączone na całej powierzchni, z wyłączeniem obszaru inicjacji detonacji materiału wybuchowego.

Tablica I. Oznaczenie próbek oraz parametry zgrzewania wybuchowego

Table I. Marking of specimens and explosive welding parameters

\begin{tabular}{|c|c|c|}
\hline Próbka & $\begin{array}{c}\text { Wysokość } \\
\text { materiału } \\
\text { wybuchowego }(\mathrm{H})\end{array}$ & $\begin{array}{c}\text { Wstępna odległość } \\
\text { pomiędzy } \\
\text { blachami (h) }\end{array}$ \\
\hline A & $30 \mathrm{~mm}$ & $5 \mathrm{~mm}$ \\
\hline B & $32 \mathrm{~mm}$ & $5 \mathrm{~mm}$ \\
\hline C & $25 \mathrm{~mm}$ & $5 \mathrm{~mm}$ \\
\hline
\end{tabular}

Tablica II. Skład chemiczny materiału podstawowego

Table II. Chemical composition of base material

\begin{tabular}{|c|c|c|c|c|c|}
\hline \multirow{3}{*}{ Gatunek } & \multicolumn{5}{|c|}{ Zawartość pierwiastków, \% wag. } \\
\hline \multirow{3}{*}{ S355J2 N } & $\mathrm{C}$ & $\mathrm{Si}$ & $\mathrm{Mn}$ & $\mathrm{P}$ & $\mathrm{S}$ \\
\cline { 2 - 6 } & 0,15 & 0,31 & 1,60 & 0,013 & 0,004 \\
\cline { 2 - 7 } & $\mathrm{N}$ & $\mathrm{Al}$ & $\mathrm{Cu}$ & $\mathrm{Cr}$ & $\mathrm{Ni}$ \\
\cline { 2 - 6 } & 0,003 & 0,040 & 0,07 & 0,08 & 0,05 \\
\hline
\end{tabular}

Tablica III. Skład chemiczny materiału nakładanego

Table III. Chemical composition of clad material

\begin{tabular}{|c|c|c|c|c|c|}
\hline Gatunek & \multicolumn{5}{|c|}{ Zawartość pierwiastków, \% wag. } \\
\hline \multirow{4}{*}{ AW-1050A } & $\mathrm{Al}$ & $\mathrm{Cu}$ & $\mathrm{Mg}$ & $\mathrm{Mn}$ & $\mathrm{Si}$ \\
\hline & 99,53 & 0,0033 & 0,0029 & 0,0316 & 0,0611 \\
\hline & $\mathrm{Fe}$ & $\mathrm{Ti}$ & $\mathrm{Zn}$ & $\mathrm{Cr}$ & \\
\hline & 0,3060 & 0,0124 & 0,0113 & 0,0016 & \\
\hline
\end{tabular}

\section{Wyniki badań $\mathrm{i}$ ich analiza}

\section{Badania geometrii złącza}

Charakterystyczną cechą zgrzewania wybuchowego jest falista budowa złącza. W pierwszym etapie badań przeprowadzono pomiary charakterystycznych parametrów granicy połączenia t.j. długość $(\lambda)$ oraz wysokość (h) fali, długość linii złącza (L) oraz pole powierzchni obszarów przetopionych (Pi). Na podstawie wyznaczonych parametrów Pi oraz $L, z$ równania (1) wyznaczona została równoważna grubość przetopień (RGP). Schemat pomiarowy przedstawiono na rysunku 1 .

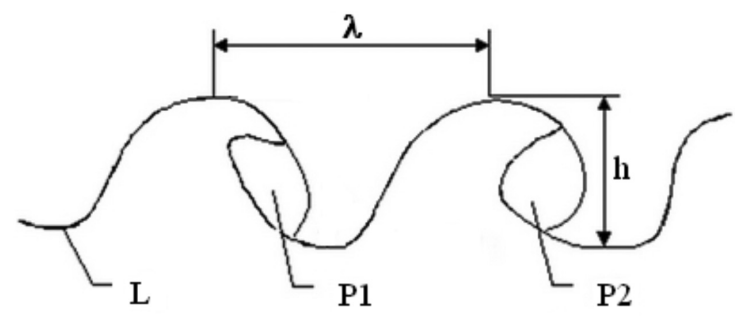

Rys. 1. Schemat fali powstałej w wyniku zgrzewania wybuchowego, gdzie: $\lambda$ - długość fali, $h$ - wysokość fali, P1 i P2- przetopienia, $\mathrm{L}$ - linia złącza

Fig. 1. Scheme wave created by the explosive welding, where: $\lambda$ - length of wave, $\mathrm{h}$ - height of wave P1 i P2- meld, L - Line of joint

$$
R G P=\frac{\sum_{i=1}^{n} P_{i}}{L}[\mu \mathrm{m}]
$$

gdzie: Pi - pole powierzchni obszarów przetopionych, $\mu \mathrm{m}^{2}, \mathrm{~L}-$ długość złącza, na którym został przeprowadzony pomiar, $\mu \mathrm{m}$.

Wyniki pomiarów geometrii złącza przedstawiono w tablicy IV. Wykazały one, że największy udział obszarów przetopionych występował w próbce A i C, dla których współczynnik RGP wynosi odpowiednio $15,78 \mu \mathrm{m}$ oraz 12,66 $\mu \mathrm{m}$. Najlepsze jakościowo złącze uzyskano $\mathrm{w}$ próbce $\mathrm{B}$, która charakteryzowała się najniższym współczynnikiem $R G P=5,45 \mu \mathrm{m}$. Połączenie w próbce $B$ charakteryzowało się najmniejszą długością fali $(L=118 \mu \mathrm{m})$, która w przypadku próbki A była sześcio-, a próbki B pięciokrotnie większa. Dla wszystkich 3 próbek wysokość fali (h) była porównywalna. Geometrię granicy połączenia dla analizowanych przypadków przedstawiono na rysunku 2.

Tablica IV. Wyniki pomiarów złącza

Table IV. The measurement results of joint

\begin{tabular}{|c|c|c|c|}
\hline Próbka & $\begin{array}{c}\text { Średnia } \\
\text { wysokość fali, } \\
\boldsymbol{\mu m}\end{array}$ & $\begin{array}{c}\text { Średnia } \\
\mathbf{d} \text { tugość fali, } \\
\boldsymbol{\mu m}\end{array}$ & $\begin{array}{c}\mathbf{R G P}, \\
\boldsymbol{\mu m}\end{array}$ \\
\hline A & 81,38 & 718 & 15,78 \\
\hline B & 70,97 & 118,7 & 5,43 \\
\hline C & 55,4 & 560 & 12,66 \\
\hline
\end{tabular}
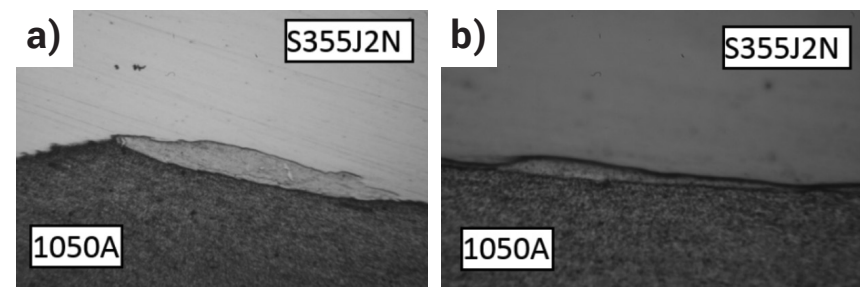

c)

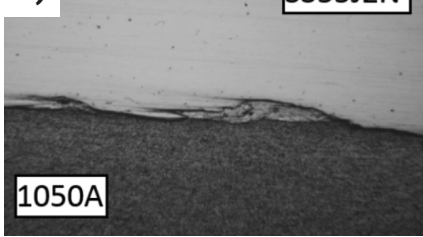

Rys. 2. Geometria złącza: a) próbka A, b) próbka B, c) próbka C. Pow. $100 \mathrm{x}$

Fig. 2. Geometry of joint: a) specimen $A$, b) specimen $B, c$ ) specimen C. Pow. $100 \mathrm{x}$

\section{Badania wytrzymałościowe}

W celu oceny własności wytrzymałościowych wykonanych układów bimetalowych przeprowadzono na maszynie wytrzymałościowej ZD20 Nr 281/58 próby odrywania i zginania bocznego. Schemat przeprowadzanych prób został przedstawiony na rysunku 3, a otrzymane wyniki w tablicy V.

Otrzymane wyniki wskazują, że wytrzymałość złącza uzyskana w próbie odrywania jest najwyższa dla próbki $A$, jednakże $w$ tym przypadku oderwanie nastąpiło w złączu. Obserwując parametry otrzymane dla próbki B, można zauważyć około $10 \%$ spadek wytrzymałości na odrywanie, ale $\mathrm{w}$ tym przypadku, próbka oderwała się w materiale nakładanym. Wskazuje to na wyższą, niż dla próbki A, wytrzymałość złącza. Próbka C, charakteryzowała się najgorsza wytrzymałością. 


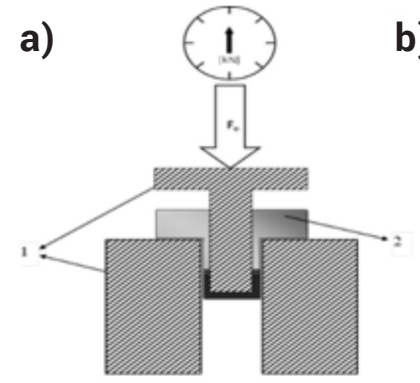

b)

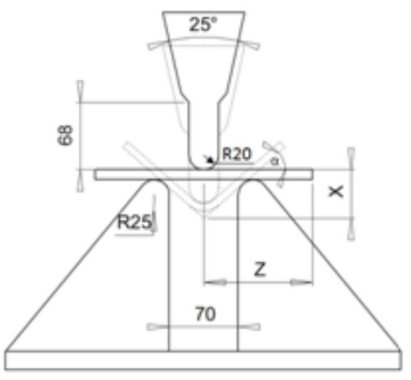

Rys. 3. Schemat przeprowadzonych prób, a) próba odrywania gdzie: 1 - elementy oprzyrządowania, 2 - próbka; b) próba gięcia

Fig. 3. Method of performing tests, a) ram strength test, where: 1 - tooling elements, 2 - tested sample; b) bend test

Tablica V. Wynik badań wytrzymałościowych Table V. Strength researchs results

\begin{tabular}{|c|c|c|c|}
\hline Próbka & $\begin{array}{c}\text { Wytrzymałość } \\
\text { na odrywanie Ro } \\
\text { [MPa] }\end{array}$ & $\begin{array}{c}\text { Miejsce } \\
\text { zerwania }\end{array}$ & Gięcie boczne \\
\hline A & 124 & Złącze & Pozytywne \\
\hline B & 112 & Al 1050A & Pozytywne \\
\hline C & 105 & Złącze & Pozytywne \\
\hline
\end{tabular}

Próby gięcia przeprowadzono zgodnie z EN13445-2 Annex D [4]. Wszystkie próbki przeszły badanie z wynikiem pozytywnym. Na powierzchni poddanej obserwacji, nie zauważono żadnych rozwarstwień oraz pęknięć.

\section{Badanie zmian mikrotwardości}

Badania te wykonano metodą Vickersa na twardościomierzu INNOVATEST NEXUS 400 przy obciążeniu 100 G. Odciski wykonano na przekroju próbki w materiale podstawowym jak i nakładanym co $200 \mu \mathrm{m}$ do odległości $2 \mathrm{~mm}$ od złącza. Wyniki przedstawiono na rysunku 4.

Wyniki badań twardości wskazują, że proces zgrzewania wybuchowego powoduje zwiększenie twardości w pobliżu linii złącza, co jest spowodowane umocnieniem obu materiałów w skutek zderzenia. Oddalając się od złącza twardość maleje. Jak widać z przedstawionych wyników dla wszystkich próbek twardości obu materiałów są zbliżone co oznacza, że wysokość materiału wybuchowego nie wpływa znacząco na twardości materiałów.

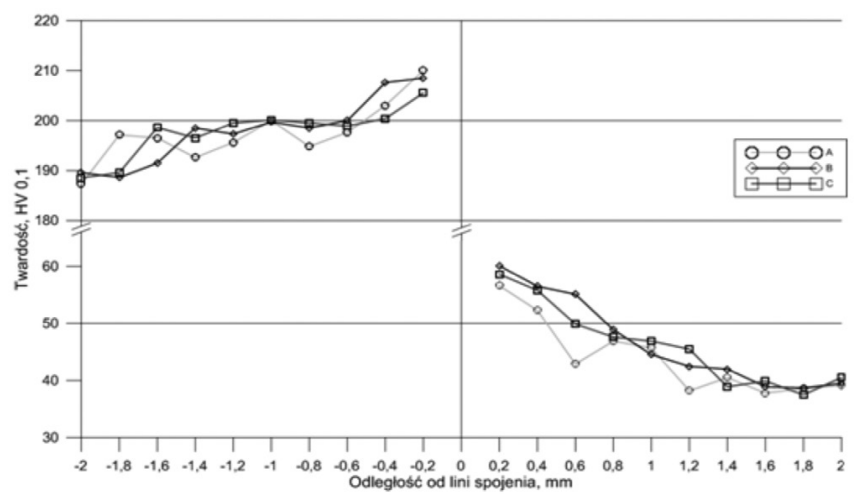

Rys. 4. Wyniki rozkładu mikrotwardości

Fig. 4. The results of micro-hardness distribution

\section{Podsumowanie}

Na podstawie przeprowadzonych badań można przedstawić następujące wnioski:

- Wysokość warstwy materiału wybuchowego mają istotny wpływ na charakter złącza.

a) Analiza przeprowadzona dla próbki A, wskazuje, że złącze cechuje się falistą budową oraz występuje większa ilość warstwy pośredniej (przetopień) niż w przypadku dwóch pozostałych płyt testowych.

b) W przypadku próbki B, złącze nie posiada charakterystycznej dla platerowania wybuchowego faliste budowy, ale udział przetopień jest najmniejszy w stosunku do dwóch pozostałych próbek oraz właściwości (próba odrywania) są najlepsze.

c) Wyniki geometrii złącz próbki C są porównywalne z wynikami tych parametrów dla próbki A, jednakże wytrzymałość na odrywanie w tym przypadku była najgorsza.

- Próba odrywania wykazała, że w przypadku próbek A oraz C zerwanie nastąpiło w złączu, zaś w próbce B w materiale Al 1050 co świadczy o większej wytrzymałości złącza niż w przypadku dwóch pozostałych. Uznaje się jednocześnie w oparciu o wyniki próby zginania, że próbka A i próbka B również spełniają standardowe wymagania dla tego typu połączeń (aluminium + stal).

- Do końcowego wytworzenia partii prototypowej i dla przyszłych realizacji wytypowano parametry procesu przyjęte dla płyty próbnej B. Uznano, że zapewniają one uzyskanie zadawalających rezultatów wytrzymałości i ciągłości złącza. Są jednocześnie dużo pewniejsze pod względem stabilnego prowadzenia procesu przy zmiennych warunkach pogodowych czy odchyłkach od geometrii układów strzałowych; nie występuje zjawisko gaśnięcia detonacji.

- Badania twardości wykazały, że wysokość materiału wybuchowego nie ma znacznego wpływu na twardości łączonych metali.

\section{Literatura}

[1] Prażmowski M., Rozumek D.: Rozwój pęknięć przy cyklicznym zginaniu w złączu cyrkon-stal powstałych w wyniku zgrzewania wybuchowego, Przegląd Spawalnictwa, nr 4, s. 45-50, 2014.

[2] Pocica N., Tuz L.: Ocena mikrostruktury i wybranych własności mechanicznych złączy zgrzewanych wybuchowo po obróbce cieplnej, Przegląd Spawalnictwa, nr 4, s. 35-38, 2016.

[3] Kwiatkowski G., Rozumek D.: Rozwój pęknięć dla różnych materiałów platerowanych wybuchowo, Przegląd Spawalnictwa, nr 4, s. 47-50, 2016.

[4] PN-EN 13455-2, 2009, Annex D, Technical delivery conditions for clad products for pressure purposes. 